\title{
Review
}

\section{Gravity at sea - A memoir of a marine geophysicist-}

\author{
By Yoshibumi TOMODA ${ }^{* 1, * 2, \dagger}$
}

(Contributed by Yoshibumi TOMODA, M.J.A.)

\begin{abstract}
A history of studies on the gravity measurements at sea in Japan is reviewed with an emphasis on the contribution of the author. The first successful measurements at sea were made in 1923 by Vening Meinesz in the Netherlands using the pendulum apparatus installed in a submarine. However, the gravity measurements using a submarine are not convenient because the access to a submarine is limited. Professor Chuji Tsuboi made a number of unsuccessful attempts at developing a gravity meter that can be operated on a normal surface ship by reducing the noise by minimizing the motion of the gravity meter through a mechanical design.

I have chosen a new approach toward the measurements of gravity on a surface ship by simplifying the mechanical part using a string gravity meter that was installed directly on a vertical gyroscope in combination with the numerical and/or electronic reduction of noises. With this gravity meter TSSG (Tokyo Surface Ship Gravity Meter), we firstly succeeded in measuring gravity at sea onboard a surface ship in July 1961 and the measurements have been extended to the northwestern Pacific and beyond. The results reveal the fine structures of gravity field in and around trenches that provide important clues as to a number of geodynamic issues including the nature of the trench-trench interaction and the interaction of trenches with seamounts.
\end{abstract}

Keywords: gravity measurement, pendulum, Vening Meinesz, surface ship gravity meter, gravity anomaly of the northwest Pacific

\section{Introduction: Gravity field of the Earth}

Gravity measurements and its interpretation have been an important branch of solid Earth geophysics. The gravity field of the Earth reflects the mass distribution in the Earth and the position at which the gravity is measured. Consequently, the gravity measurements can be used to determine the shape of the Earth and the mass distribution inside of the Earth. For example, in contrast to the theory of I. Newton (1643-1727) that the shape of the Earth is an oblate body which had swollen in the direction of the equator, J. Cassini (1677-1756) insisted that the shape of the Earth was longer along the north-south

*1 The Japan Academy, Tokyo, Japan.

*2 Published posthumously, see the editorial at the end of the text.

Correspodence to Hiromi Fujimoto, Research Center for Prediction of Earthquakes and Volcanic Eruptions Graduate School of Science, Tohoku University, 6-6 Aza-Aoba, Aramaki, Aoba-ku, Sendai 980-8578, Japan (e-mail: fujimoto@aob.gp. tohoku.ac.jp). axis of the Earth based on the triangulation survey in France. Then French Academy dispatched measurement corps to Peru in South America including P. G. Bouguer (1698-1758) and another corps to Lapland in northern part of Scandinavia peninsula led by P. L. Maupertuis (1698-1759) in 1735-1743. These measurements established that the Earth has a larger radius at the equator than at the poles as was proposed by Newton. This was the turning point when the theory of gravity and the shape of the Earth by Newton were basically accepted in France.

Also P. G. Bouguer later discovered the influence of attraction of underground structure on gravity, and established the foundation of the idea of isostasy. The concept of isostasy was later investigated in more detail by G. B. Airy and J. H. Pratt. The concept is that the surface topography is associated with a root of the light crustal material penetrating into the dense mantle so that the gravity due to the excess mass of a mountain is nearly cancelled out by the presence of a relatively light crustal material in the mantle. 
A Dutch geophysicist C. Huygens (1629-1695) invented a precise clock by using a pendulum. He also showed possibility of precise gravity measurement by calculating the period of a pendulum. Then the gravity on the surface of the solid earth was measured by using gravity pendulums.

Although these measurements have made important contributions to our understanding of the Earth including the shape of the Earth and the concept of isostasy mentioned above, the land covers only $\sim 30 \%$ of the surface of the Earth; it was essential to extend the gravity measurements to the area covered by the sea. The shape of the Earth could be measured on land by two methods: change in gravity or in the direction of vertical at a certain distance along a meridian. However, gravity was the unique method to measure the shape of the Earth in the ocean.

Gravity measurements also provide direct constraints on the mass distribution in the Earth from which one can infer the processes controlling the mass distribution such as the style of mantle convection and the distribution of mechanical properties inside the Earth. Global distribution of gravity was firstly measured on board submarines. After the launch of the Sputnik 1 in 1957, ground-based tracking of satellite orbit perturbations became a principal method to study the gravity field in the wavelength longer than a thousand kilometers. Sea surface gravimetry remained crucial in the field of shorter wavelengths. Although satellite altimetry has become another important method for gravity mapping in wavelengths shorter than a hundred kilometers, sea surface gravimetry combined with detailed bathymetry is indispensable for the study of submarine structures.

As is shown in Fig. 1, gravity value on the Earth can be estimated without a measurement to the precision of $10^{-4}$ from the information of the latitude and the altitude of the observation point. That is why we use a standard gravity formula on the Earth's surface, which is called the normal gravity. Deviation of an observed value from the normal gravity is called a free-air gravity anomaly. Because meaningful information is in the 5 th or lower digits of measured values, precision is critical to the successful measurements of the gravity field. To understand the necessary precision, let me take an example of the magnitude of free-air gravity anomalies: one of the largest anomalies on the Earth is those around ocean trenches and are on the order of 100 mgal ("gal" is the unit of acceleration in the CGS unit after Galileo: $1 \mathrm{gal}=1 \mathrm{~cm} \mathrm{~s}^{-2}=10^{-2} \mathrm{~m} \mathrm{~s}^{-2}$ ). Normal gravity is $\sim 980$ gals or 980,000 mgals. In the case of the trench,

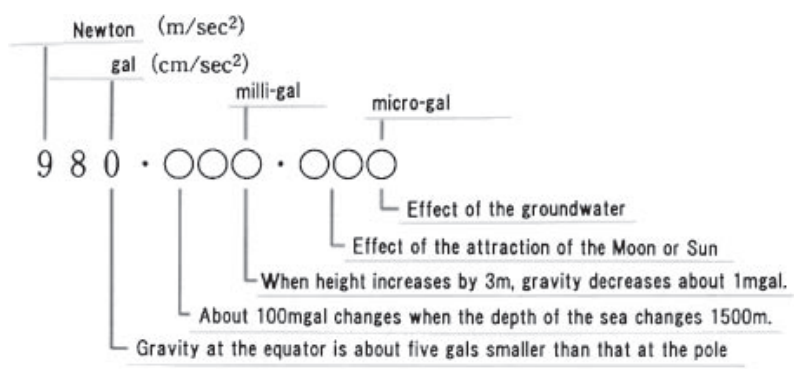

Fig. 1. Influence of natural phenomena on gravity. Gravity changes with latitude chiefly due to the variation in the centrifugal force. The change is about five gals from the equator to the poles. It also changes with elevation at the rate of $0.3086 \mathrm{mgal} / \mathrm{m}$. Therefore, when height increases by $300 \mathrm{~m}$, gravity decreases about 100 mgals. Moreover, gravity changes with the structure beneath the surface of the Earth. Gravity changes by about 100 mgals when the depth of the flat seafloor is changed by $1500 \mathrm{~m}$ without isostatic compensation. This is due to the density difference between the crust and the sea. The density of seawater is $1030 \mathrm{~kg} \mathrm{~m}^{-3}$ while the average density of the crust is about $2670 \mathrm{~kg} \mathrm{~m}^{-3}$. The influence of the moon and the sun is $0.1-0.01$ mgal and it changes with time. In the digit of micro-gal, many natural phenomena such as the attraction of ground water or that of the atmosphere gives effects. Therefore, it is usually not so easy to identify the origin of them.

in order to determine the gravity anomaly with $\sim 10 \%$ error, one needs to determine the gravity to the precision of $\sim 10$ mgal. For other regions, gravity anomalies are smaller. Consequently, a typical goal of precision in gravity measurements for geophysical studies is $1 \mathrm{mgal}$ ( $\sim 1 \mathrm{ppm}$ of normal gravity). Influence of natural phenomena on gravity is shown in Fig. 1.

The main sources of errors in gravity measurements are the accelerations caused by irregular motions of a gravimeter as well as errors in measuring the observable such as the period of oscillation. The ground shakes when an atmospheric low pressure approaches, if it is covered with a thick sedimentary layer like in Tokyo. Then the accuracy of measurement of gravity decreases with errors in the seventh or eighth digit. However, irregular motions of a ship can cause large errors in gravity measurements in the second digit ( 10-100 gal). The difficulty of gravity measurement with a precision of $1 \mathrm{mgal}$ is similar to that of measuring your weight to the accuracy of 0.1 gram on a ship sailing in the rough sea.

\section{Measurement of gravity at sea on board submarines ${ }^{1), 2)}$}

In 1923, Vening Meinesz (1887-1966) of the Netherlands succeeded, for the first time, in the measurement of the gravity at sea with significant precision useful for geophysical studies (with the 
precision of 4-5 mgals). Difficulties in gravity measurements in the swampy ground in Holland led to the development of a system for marine gravimetry. An important step was a method of swinging two pendulums with the same amplitude but in opposite phases. The principal effect of the soft ground is associated with horizontal accelerations, which can be eliminated by measuring the relative motion of two pendulums. The success of this method on land led to an investigation of possibilities of gravity measurement at sea. Vening Meinesz put a pendulum apparatus on a submarine following the advice by Professor Van Iterson, Director of the Dutch Government Mines, that there is less motion on a submarine under submergence. Even during rough weather, a submarine is sufficiently quiet at a depth of $30 \mathrm{~m}$ or more. A further advantage is that during submergence it is moved by electro-motors, which do not bring about large vibrations as a diesel engine in a normal ship does. However, the acceleration due to the movement of submarine under the sea is small but not zero. Consequently, he used two methods to obtain the desired precision. Firstly, the pendulum device was kept vertical with gimbals on two axes (because gravity is the acceleration in the vertical direction, keeping the vertical direction is essential). Secondly, he used a set of three pendulums; the central one was hung freely and the pendulums on both sides swung with the same amplitude but opposite in phase. Two sets of data showing the differential motion between the central pendulum and that on each side were used to calculate the gravity.

Vening Meinesz started developing a gravimeter system in 1920, and carried out the first expedition from Holland to Java on board a submarine in 1923, the same year when the great Kanto earthquake occurred. Soon after the departure from the mother port, they repaired the device at the British navy base in Gibraltar. Combined with the observation during the cruise in 1926-1927, a complete ring of gravity values, encircling the Earth, were obtained for the first time, and it was found that the gravity anomaly was quite small in most of the oceans (less than $\sim 10$ mgals or about $10 \mathrm{ppm}$ of a gravity value). Recognizing that the understanding the relation between gravity and tectonic activity would be of primary importance, he carried out an especially detailed study in the Java Trench near Indonesia that had been a Dutch territory. The seafloor topography was also measured with echo sounders at more than 30,000 points. Then he found that the gravity along the Java Trench is more than 100 mgals smaller than the normal value. According to Professor Chuji Tsuboi who was a member of the Japan Academy, this was one of the most important discoveries in geophysics in the 20th century, and had a big influence on the research of the earth's crustal structure and mantle convection that followed. For example, Vening Meinesz interpreted that the large negative anomalies of gravity is caused by the thickened crust deformed by the force associated with the downgoing convection current beneath the trench. He was one of the first geophysicists to advocate the concept of mantle convection (for the detailed discussions on the study of mantle convection based on gravity measurements, see Heiskanen and Vening Meinesz ${ }^{2)}$ ).

After the second World War, Vening Meinesz's apparatuses were distributed all over the world and installed on 27 submarines released from the war. Professor J. L. Worzel conducted a global-scale oceanic gravity measurements. ${ }^{3)}$ The results became the basis of global database of gravity that the geophysicists had dreamed of for a long time.

The gravity measurement at sea was also advanced in Japan. The Sanriku district in the northeast Japan was flooded by a "Tsunami" due to an earthquake that occurred in the Japan Trench off the district in March 1933. In the next year, "the Geodetic Committee of Japan" imported the Meinesz's apparatus from the Netherlands (Fig. 2). Professor Motonori Matuyama installed the device on a Japanese submarine as is shown in Fig. 3 and measured the gravity around the Japan Trench. $\left.{ }^{4}\right)$ Figure 4 shows the submarine "Ro-57". He also measured the gravity over the Izu-Ogasawara Trench in the following year. I have deep respect to Professor Matuyama for determining the gravity distribution of the island arc and the trench system around Japan, about ten years after Vening Meinesz invented the apparatus.

\section{Early unsuccessful trials to measure gravity on a surface ship}

3.1 Early studies in Professor Tsuboi's laboratory. Recognizing the limitations of submarine measurements of gravity field, several groups of scientists tried to develop new techniques for measuring the gravity field on board a normal surface ship. If such measurements became possible, a huge amount of new data would be obtained at sea that should help advance our understanding of the dynamics of the Earth. However, even with the submarine with far less motion compared to a normal surface ship, 


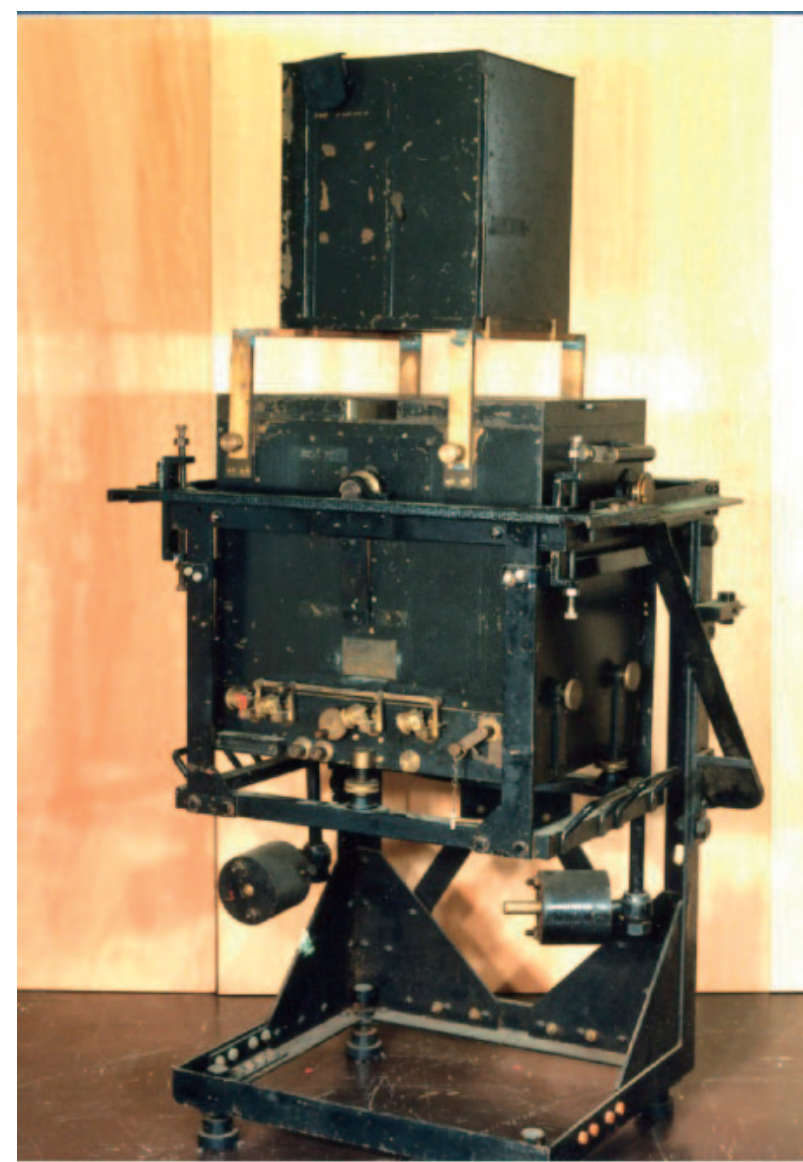

Fig. 2. The Vening Meinesz's gravity pendulum apparatus. The one exhibited at the one hundredth year anniversary of the International Geophysical Year. The Geodetic Committee of Japan imported this apparatus from the Netherlands in 1934.

Vening Meinesz had to struggle with the errors in gravity measurements caused by the motion of a submarine. Therefore, you can easily understand that it is quite difficult to measure gravity on a surface ship, which shakes like a leaf in the rough sea.

In order to reduce the influence of the motion of ship on the gravity measurements, Professor Tsuboi designed gimbals, which do not shake easily like a balancing toy called "Yajirobei" that is like a long period horizontal pendulum having a longer period than the period of the ship's movement. This device became patented by the navy. With this apparatus, Professor Tsuboi and his colleagues tried to measure gravity onboard the moving passenger boat "Aoi-maru" in 1933. ${ }^{5)}$ I heard from one of the members that the situation was far from measuring gravity, but the pendulums fell from its base. This was a year before Professor Matuyama imported the

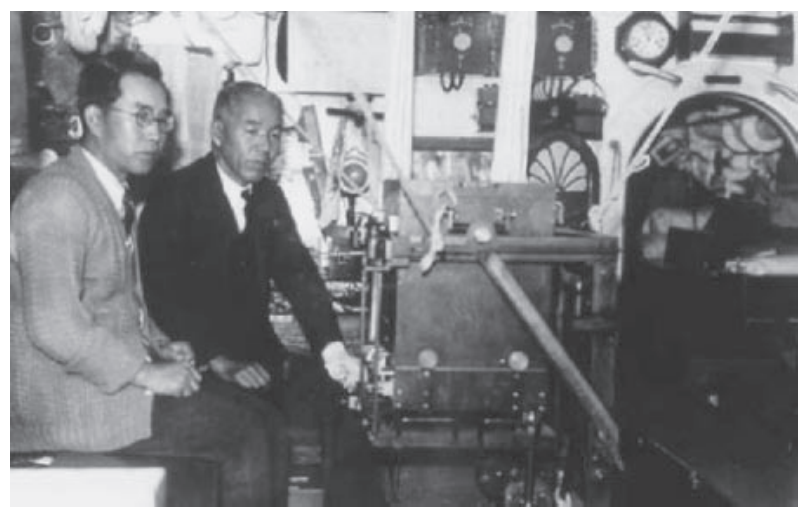

Fig. 3. The gravity pendulum and Professor Motonori Matuyama. The Meinesz's pendulum apparatus placed in the commanding tower of the Japanese submarine "Ro 57". On the right is Professor Motonori Matuyama, and on the left is Naoichi Kumagai (technical associate at that time). The submarine set sail from Yokosuka naval port in a drizzle on October 17, 1934. The team measured three or four dives a day, 27 times during a total 25 dives crossing the Japan Trench six times.

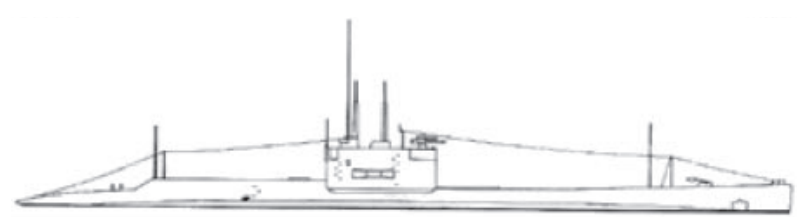

Fig. 4. The submarine "Ro-57". Standard displacement 889 tons, displacement in water 1103 tons, total length $77 \mathrm{~m}$, maximum width $7 \mathrm{~m}$, speed (sea surface) $17 \mathrm{knots}$, (submerged) $9 \mathrm{knot}$, cruising range 5500 nautical miles with speed of 10 knots, maximum submergible depth of $60 \mathrm{~m}$, completed in 1922 .

instrument for a submarine. I suppose that such experience made a tenacity of Professor Tsuboi to support my effort perseveringly for more than ten years to complete the gravity meter that works on a surface ship.

3.2 My early studies on a sea gravity meter. When I graduated from the university and became a research assistant to Professor Tsuboi in 1950, several senior scientists had been working in Professor Tsuboi's laboratory to improve a pendulum system for accurately recording a seismic signal; the key was a stable frequency to rotate the drum of the recorder. The chief of the program was Mr. Tamio Kuyama, technological colonel of the navy, graduated from Department of Physics, University of Tokyo (later Professor of The National Defense Academy, division of Underwater Acoustics). I followed up his studies. 
In 1951, we started to test a surface ship gravity meter, using a short-period bifilar pendulum gravity meter. In this pendulum, an inertia rod is suspended by a pair of thin strings attached at both ends of the rod, and a weight is suspended at the center of the rod. The weight was equipped with a damper to reduce the effect of the ship's motion. The frequency of oscillation of the rod increases with the weight of the mass and the distance between the two strings, and decreases with the length of the string and the moment of inertia of the rod. One of the important characteristics of the pendulum is that it is easy to make a high frequency (about $10 \mathrm{~Hz}$ ) pendulum by increasing the mass and decreasing the moment of inertia of the rod. A high-frequency pendulum was useful for measuring frequency by comparing with the frequency of a reference clock as is mentioned below. Higher frequency was also important for reducing the effects of ship's motion with period of 5-20 sec. A gimbal with a damper like that used in Vening Meinesz's gravimeter was used to keep the gravity meter vertical.

The frequency-measuring equipment was designed to measure the frequency of the pendulum relative to a reference clock within the accuracy of $5 \times 10^{-7}$ in $10 \mathrm{~min}$, required for gravity measurement at precision of $1 \mathrm{mgal}$. An accurate clock was one of key technologies in the gravity measurement. In the pendulum gravity measurement by submarines, they used a marine chronometer. The submarine surfaced twice a day to receive a "time signal" sent by radio to calibrate the chronometer. An accuracy of about $5 \times 10^{-6}$ (about 0.1 seconds error in a day) can be obtained by doing so. In the measurement of gravity by Japanese submarines, time of surfacing of the submarine was ten o'clock in the morning when the radio signal for the clock calibration was sent from the Haranomachi wireless system bureau in Fukushima Prefecture.

The integrated gravity pattern was directly displayed on the recording paper by comparing the frequency of the bifilar pendulum with that of the reference clock. The signal from the pendulum (some $10 \mathrm{~Hz}$ square wave) was firstly shaped into some $20 \mathrm{~Hz}$ pulses by differentiating and rectifying, and then multiplied into some $60 \mathrm{~Hz}$ by means of an electronic frequency multiplier. The signal drove a synchronous motor. Another synchronous motor was driven by the $60 \mathrm{~Hz}$ signal of the clock. The recording drum was driven by the difference in revolution of the two synchronous motors with the aid of a differential gear equipment. The variations in acceleration of gravity were then detected within an accuracy of 1 mgal through the variations in revolution of the drum measured with marks at a constant time interval on the recording paper.

At an early stage of the gravity meter, the reference clock was a chronometer, signals from which were sent every $0.5 \mathrm{sec}$. The frequency was multiplied close to that of the pendulum. Seeing my acrobatic operation, Professor Issaku Koga (member of the Japan Academy at that time), the pioneer of the quartz clock in Japan, told Professor Tsuboi "the quartz clock is the best for this research". He kindly made the third quartz clock in Japan for this purpose. It became the reference clock of the system. Dr. Takashi Nakata of Tokyo Institute of Technology (assistant professor at the time and the later member of the Japan Academy) designed the "twisted bevel gears" that were important parts of the differential gear in the recording system.

Six years passed before the first sea trial. At last we tried to measure gravity at sea using this type of gravity meter in 1957 . The ship was "Kaiyo" (270 tons) of the Hydrographic Department, Maritime Safety Agency (present Hydrographic and Oceanographic Department, Japan Coast Guard). The test was unsuccessful due to the problems both in the gravity meter and in the ship's facility. Scientists now on board a modern research ship use electricity as if an electric power company supplies electricity. However, the situation with the ship in 1957 was far from this. The capacity of electric power supply was small and the voltage fell to about $30 \mathrm{~V}$ when the switch of the gravity meter was turned on, and we could not increase the voltage even when the handle of the voltage transformer was turned. There was little space to install the gravity meter in the ship. Therefore, it was loaded in the "bow hold" of the ship, where the effect of the pitching was the largest. Ventilation there was bad and filled with the smell of paint. It was like a slave ship at rough sea.

After another unsuccessful test cruise in 1957 on board "Ryofu-maru" (1,200 tons) of the Meteorological Agency (Fig. 5), we developed the second model in 1958 and revised it next year. A major improvement was made in the gimbal suspension. It was so designed that an averaged value of horizontal accelerations was fed to the torque motors to keep the gimbal horizontal. By choosing an appropriate time constant for the integrating circuit, it might be possible to have the gimbal be astatic for horizontal accelerations in shorter period and active in period longer than $20 \mathrm{~s}$ or so. We tried to measure gravity 


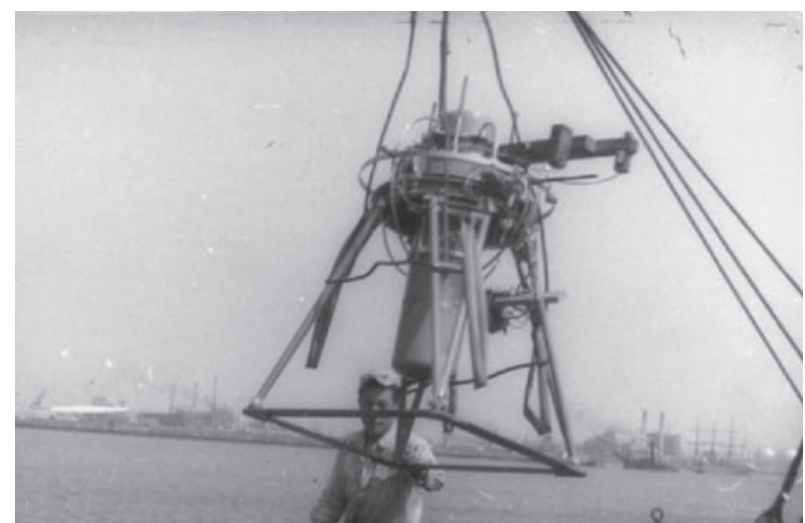

Fig. 5. Loading the bifilar gravity pendulum on "Ryofu-maru". We set up the "bifilar gravity pendulum" in the hold of "Ryofumaru" of the Meteorological Agency which was anchored in Harumi wharf.

across the north Pacific in 1960 on board the cargo ship "Meirinsan-maru" (7,700 tons) of the Mitsui Senpaku Co. Ltd. However, we could not get successful results again. In those days, we knew little about the sea and the ship, and expected that the motion would probably be small if the ship was large and that everything might go well. Now I wonder if those machines were able to work had we chosen a calm sea. The lesson learned from these failures is that we must design the system in such a way that it must work perfectly under irregular motions of a ship. The most serious problem was how to keep the gravity meter vertical in such a condition.

\section{Measurement of gravity on a surface ship}

4.1 String gravity meter stabilized with a gyroscope. ${ }^{6}$ In addition to the improvements on the clock just mentioned, the major breakthrough in the development of the surface ship gravity meter TSSG (Tokyo Surface Ship Gravity Meter) resulted from two improvements: (i) to simplify the mechanical component of the gravity meter, and (ii) to reduce the influence of the movement of the ship through electronic and/or numerical approaches using a low-pass filter. A vertical gyroscope was adopted to keep the instrument vertical; it is a lesson learnt from the experiments by Professor Tsuboi that the machines that did not adopt this method failed. I decided to use a compact vibrating string gravity sensor rather than a more massive pendulum gravity meter and set the gravity sensor directly on a gyroscope. However, there was neither a vertical gyroscope nor a book on it. As for the calculation of the numerical filter, "on-line" use of a computer would have easily solved the problem. When I started this work, however, a computer to conduct data reduction was not readily available as is explained below.

One day, when I looked around the electric junk stores in the street of Kanda, I happened to find a curious apparatus. The device seemed to be a vertical gyroscope for an airplane. The owner of the junk store told me that these were vertical gyroscopes for horizontal navigation of the bombers used in the Korean War. The price of a complete set was 6,000 yen. I bought four sets of them. They were products of "Honeywell". I disassembled one set completely, and investigated how it works. Professor Hisashi Kinbara at the First High School (present Division of General Education, University of Tokyo) introduced me to his colleague Professor Matao Sanuki who was a specialist of aviation instruments. He took it to Nihon Kouku Denshi Co. (Japan Aviation Electronics Industry) and brought it back to our laboratory in virtually brand new condition. I used it for the prototype shipboard gravity meter as is shown in Fig. 6.

The vibrating string gravity sensor of the TSSG works in the following way. A small mass is suspended by a thin string. When the string vibrates in a magnetic field, it induces the voltage, which is fed back to the string to continue the vibration. Natural frequency of lateral vibration of the string depends on the force acting at the end of the string that is proportional to the mass and the acceleration of gravity. Therefore by measuring the frequency of the vibration, one can determine a change in gravity. Precise values of the weight of the mass and the length of the string are not necessary for relative gravity measurements. This type of gravity meter was firstly developed by R. L. Gilbert and was tested on board a submarine in 1948. ${ }^{7}$ ) A new device in the TSSG uses two pairs of cross-spring horizontally attached to the weight so that no pendulous swinging of the weight is caused by the motion of the ship.

A weight of twenty-five grams is suspended by a string ribbon made of beryllium copper of $0.01 \mathrm{~mm}$ in thickness and $0.2 \mathrm{~mm}$ in width. Beryllium copper was adopted due to its stable characteristics in elasticity although it was more expensive than gold in those days. Smooth surfaces of the ribbon were essential to make a stable gravity meter. To make a ribbon with smooth surfaces, the wire was rolled out in the first rod just after polishing the roller. A small town factory in Oome city kindly undertook this job. The string must vibrate in the high vacuum, and Mr. T. Kishii in Toshiba Central Research Institute, who 


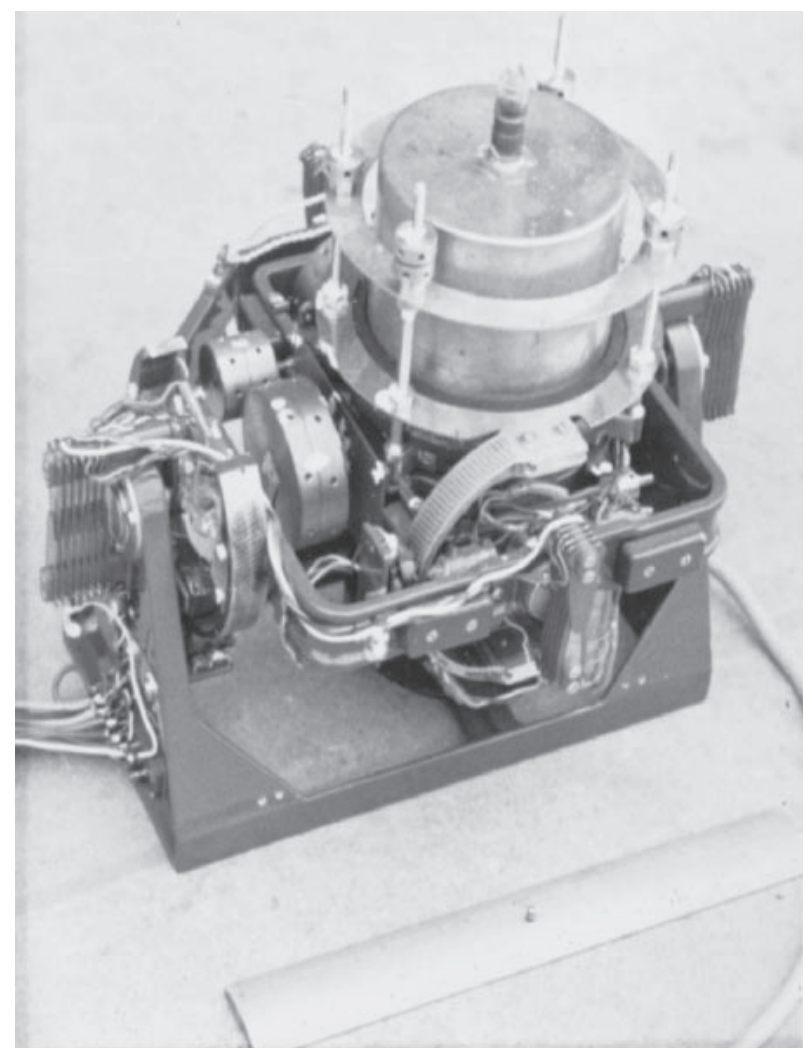

Fig. 6. The first model of the string gravity meter TSSG-60. A vertical gyroscope for the horizontal navigation of an airplane was remodeled and the string gravity meter was installed directly on it. The string was placed in an electronically controlled housing of constant temperature. With this gravity meter, we succeeded in measuring gravity at sea from Tokyo to Miyakejima Island in July 1961. Length of the scale in the photograph is $20 \mathrm{~cm}$.

was working in the department of glass processing technology of the vacuum tube, gave us good advices on how to maintain a high vacuum condition. Because temperature was the most important physical parameter, the string was contained in a temperature-regulated housing.

The period of vibration of the string was measured alternately by two counters and punched on line onto a paper tape at highest punching ability (18 bits about every $0.5 \mathrm{~s}$ : 6 bits in 3 rows every $0.5 \mathrm{~s}$ ) at that time. The punching machine worked steadily spending four roles of paper tapes a day and made small holes on the paper strip. Seeing that small round scraps accumulated in a wastebasket, one of the sailors asked us "Is it the purpose of this machine to make the small, wound paper scraps?"

4.2 Numerical data processing. ${ }^{6)}$ As is mentioned above, natural frequency of lateral vibra- tion of the string gravity meter varies according to the acceleration of gravity. Therefore relative value of gravity can be determined by measuring the period of the vibration. There are three necessary data processing steps for the string gravity meter. The first is the conversion from the period to the gravity with corrections for the effect of the elasticity of the string and the elastic effect of the leaf spring that supports the mass. As a result, the acceleration of gravity is expressed with the period as Eq. [1]. The second is the numerical low-pass filtering to separate a gravity change from the vertical motions of a ship. The filtering is a kind of convolution of a series of measured values of the acceleration and a weight function that is the Fourier transform of the frequency characteristics of the low pass filter. The third point is that what we measure is not an instantaneous period but a mean period during a certain finite sampling interval. Considering that gravity is not a linear function of the period as is shown in Eq. [1], the sampling interval must be sufficiently short. On the other hand, sampling interval is limited by the speed of measurement of the period and the data processing as shown in Eqs. [1] and [2]. The effect of the finite sampling interval is expressed in Eq. [3]. Suppose that a typical example of strong ship's motion is about 100 gals with a period around several seconds, then the second order correction is necessary if the sampling interval is longer than $0.02 \mathrm{~s}$. Mathematical expression of these processing is as follows:

1) Relation between the vibration period $T_{s}$ and the gravity value $g$ is,

$$
g=\frac{K_{1}}{T_{s}^{2}}+\frac{K_{2}}{T_{s}}+K_{3}
$$

where, $K_{1}, K_{2}$, and $K_{3}$ are constants.

2) Separation of gravity and short period vertical accelerations due to the ship's motion:

$$
\begin{gathered}
\overline{G(\omega)}=G(\omega) * F(\omega) \\
F(\omega)=F\left(\frac{2 \pi}{T}\right)=\frac{\sin \pi\left(\frac{T_{1}}{T}\right)}{\pi\left(\frac{T_{1}}{T}\right)} * \frac{\sin \pi\left(\frac{T_{2}}{T}\right)}{\pi\left(\frac{T_{2}}{T}\right)} * \frac{\sin \pi\left(\frac{T_{3}}{T}\right)}{\pi\left(\frac{T_{3}}{T}\right)} \\
g(t)=\frac{1}{2 \pi} \int_{-\infty}^{\infty} G(\omega) e^{-i \omega t} d \omega \\
\overline{g(t)}=\frac{1}{2 \pi} \int_{-\infty}^{\infty} \overline{G(\omega)} e^{-i \omega t} d \omega \\
=\frac{1}{2 \pi} \int_{-\infty}^{\infty} G(\omega) * F(\omega) e^{-i \omega t} d \omega \\
G(\omega)=\int_{-\infty}^{\infty} g(t) e^{i \omega t} d t
\end{gathered}
$$




$$
\begin{gathered}
\overline{G(\omega)}=\int_{-\infty}^{\infty} \overline{g(t)} e^{i \omega t} d t \\
\overline{g(t)}=\int_{-\infty}^{\infty} g(t) * \varphi\left(t-t^{\prime}\right) d t^{\prime} \\
\varphi(t)=\frac{1}{2 \pi} \int_{-\infty}^{\infty} F(\omega) * e^{-i \omega t} d \omega
\end{gathered}
$$

Where $T_{1}, T_{2}$ and $T_{3}$ are characteristic periods of the filter. We adopted the following values: $T_{1}=60 \mathrm{~s}, T_{2}=90 \mathrm{~s}$, and $T_{3}=120 \mathrm{~s}$, by which we can reduce the noise of $5 \mathrm{~s}$ signal by a factor of $\sim 1 / 150000$.

3) Second order correction for the sampling interval,

$$
\begin{gathered}
\Delta g_{\mathrm{z}}(\tau)=\frac{1}{8} \frac{A^{2}}{g_{0}}\left[1-\left(\frac{\sin \pi\left(\frac{\tau}{T_{0}}\right)}{\pi\left(\frac{\tau}{T_{0}}\right)}\right)^{2}\right] \\
A=\sqrt{\frac{\sum\left(g-g_{0}\right)^{2}}{\mathrm{~N}}}
\end{gathered}
$$

Where $\tau$ : the sampling interval of the period of the string vibration,

$A$ : r.m.s. amplitude of the irregular vertical accelerations (set to a certain value according to the sea state in the early stage of the data processing),

$T_{0}$ : average period of the vertical motion of the ship,

$g_{0}$ : gravity value obtained in the previous processing, and

$\Delta g_{\mathrm{z}}(\tau)$ : the second order correction.

4.3 Success in the observation at sea. The first model TSSG-60 was completed in 1960. The first test of the instrument was carried out in July, 1961, on board "Takuyo" (700 tons) of the Maritime Safety Agency. It was a new and powerful survey ship with the power supply of the AC100 voltage sufficient to drive our gravity meter; many patrol boats and the survey ships at that time had only the power supply necessary for illumination. Unlike the "Kaiyo" mentioned above, we could set up the machine in the "Master gyro room" that was near the center of the gull on the ship. By the way, the Emperor Showa used this ship to collect living organisms on the bottom of Sagami Bay and His Majesty's Seat Place had been equipped.

The cruise of "Takuyo" from Tokyo to Miyakejima Island was the commemorative voyage during which we carried out the first successful measurement of gravity at sea on board a surface ship in Japan. ${ }^{8)}$ Fortunately, the mechanical part of

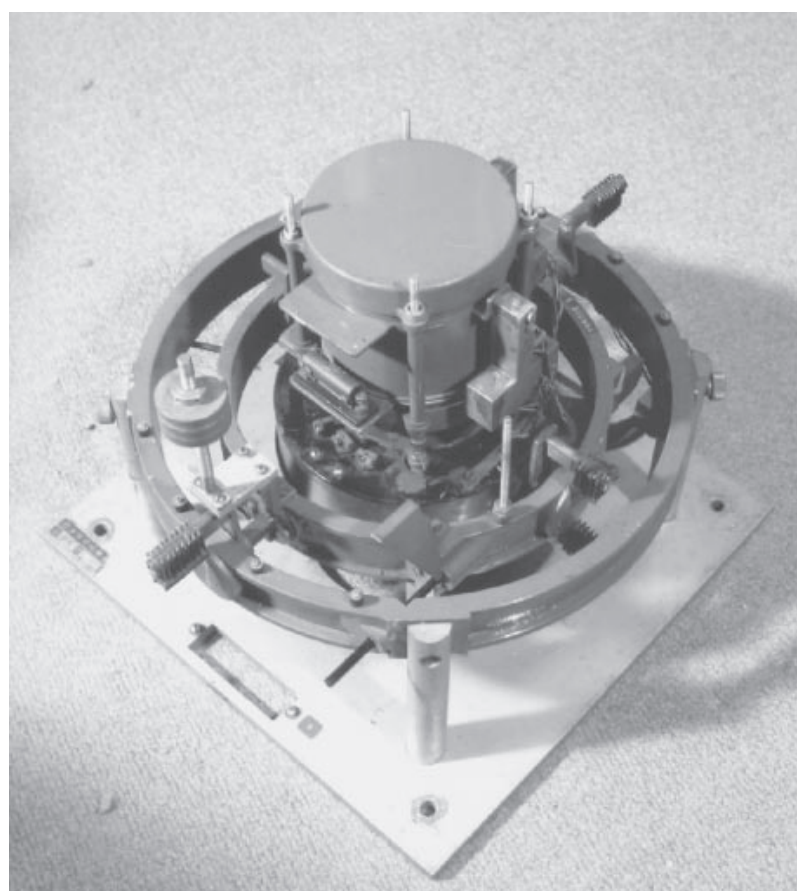

Fig. 7. The second model TSSG-63. The vertical gyroscope was made by using a spinning top for gyrocompasses used for shipboard navigation, instead of a secondhand device used by an airplane. This gravity meter was installed in 1967 on the research ship "Hakuho-maru" of the Ocean Research Institute, and took an active part in the gravity measurement of the Japan Sea. When I was awarded the Japan Academy Prize, it was exhibited in the hall of the Academy.

the first model was stored without being thrown away, and was received by The National Science Museum though it had been covered with dust of ten years in a corner of my laboratory. We developed the second model TSSG-63 in 1963 (Fig. 7). To reduce the influence on the gyroscope we minimized the size and weight of the string gravity meter; the length of the string was shortened from $30 \mathrm{~mm}$ to $25 \mathrm{~mm}$. It was on board "Umitaka-maru" (1500 tons), Tokyo University of Fisheries, for the period 1963-67. In 1967 it was installed on "Hakuho-maru" (3200 tons) of the Ocean Research Institute, University of Tokyo.

We were able to get a gravity value by the calculations in Eqs. [1]-[3] after reading the paper tapes. However, to tell the truth, there was no working computer when the paper tapes were at hand. You may think that the Universities were too poor to buy an electronic computer, but the fact is that there were few computers that worked well at that time in Japan. The data punched on paper tapes in the binary system could not be read by an NEC computer at the Calculation Center of the Ministry 
of International Trade and Industry in Nishikubo Tomoe-cho. In the end, we borrowed a tape reader and a puncher from the Electro-technical Laboratory (a division of National Institute of Advanced Industrial Science and Technology: AIST), and made two kinds of copies from the original paper tapes: one for three higher digits and the other for three subordinate digits. The two tapes were read separately, and synthesized inside the computer. A programmer Mrs. Kinko Yamamoto (later managing director of the Japan Information Processing Development Center) proposed this method.

4.4 Challenge of installing a computer on the ship. In the fourth Antarctic sea research over five months in 1966-1967 by "Umitaka-maru", we attempted an online use of a Parametron office computer with a memory size of 300 words. Remodeling the input circuit, we connected the output from the gravity meter directly to the computer. It was impossible to execute the filtering calculation expressed in Eq. [2] online, due to the memory shortage of the computer. Therefore, we adopted the following calculation though accurate results were not to be expected in the rough sea.

$$
F(\omega)=\frac{\sin \pi\left(\frac{T_{1}}{T}\right)}{\pi\left(\frac{T_{1}}{T}\right)} * \frac{\sin \pi\left(\frac{T_{2}}{T}\right)}{\pi\left(\frac{T_{2}}{T}\right)}
$$

The actual calculation is a convolution of input acceleration data and the triangular weight function that is the Fourier transform of the formula [4]. The weight function is triangular when $T_{2} \geq T_{1}$ and easily calculated by adding or subtracting " 1 " in each step. One of the troubles during the cruise was not the computer itself but the output typewriter, that the rolling and pitching of the ship often forced it to stop or move its carriage.

In 1967, the Ministry of Education allocated the budget of the computer for the newly built research vessel "Hakuho-maru". It aimed leading the world in the measurement of the gravity at sea. Dr. Toshio Ikeda of Fujitsushin (Fujitsu) Co., who was the pioneer of computer in Japan, literally beating his chest, introduced us the computer FACOM 270-20. The computer was a 16-bit machine made under a new concept. He explained that this model was used for selling tickets online in Tokyo Race Course. The computer was set up in the ship completed in 1967 (Fig. 9). We succeeded in connecting the output of the gravity meter to the computer online next year. Calculated gravity result was recorded every 5 minutes on a magnetic tape of the computer; it was

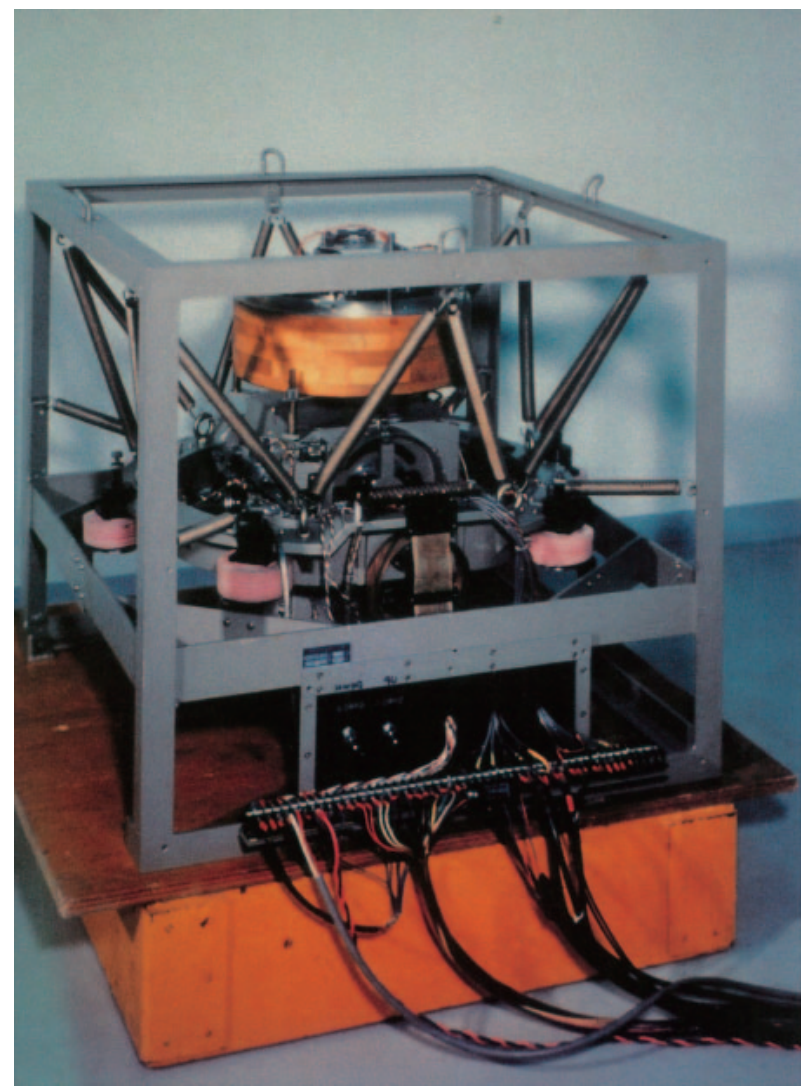

Fig. 8. The third model TSGG-72. The gyroscope using two tops improved the accuracy of the instrument's vertical. The string gravity meter was the same as the second model. The gravity meter generated a great deal of gravity data through all the cruises of "Hakuho-maru" for nine years starting from 1974.

no longer necessary to record the measured period every $0.5 \mathrm{~s}$ on the paper tapes.

This machine was indeed tough to use. The cooling water pipe for the air conditioner in the computer room was damaged from electric erosion during a cruise in the East Pacific in December, 1968. The seawater flowed indoors for about 30 minutes, and flooded up to the height of the electronic circuits of the computer. Then, after washing and drying the printed circuits in the bathroom, we switched on the machine. "Bingo!" Operation started, calculation became possible. Thereafter, we continuously used it until returning to Tokyo port. This story is an episode that was even passed down in-house at Fujitsu Co.

In 1972, we developed the third model TSSG-72 with a major revision in the gyroscope (Fig. 8). To improve the accuracy of the instrument's vertical, an automated vertical gyroscope was produced by using 

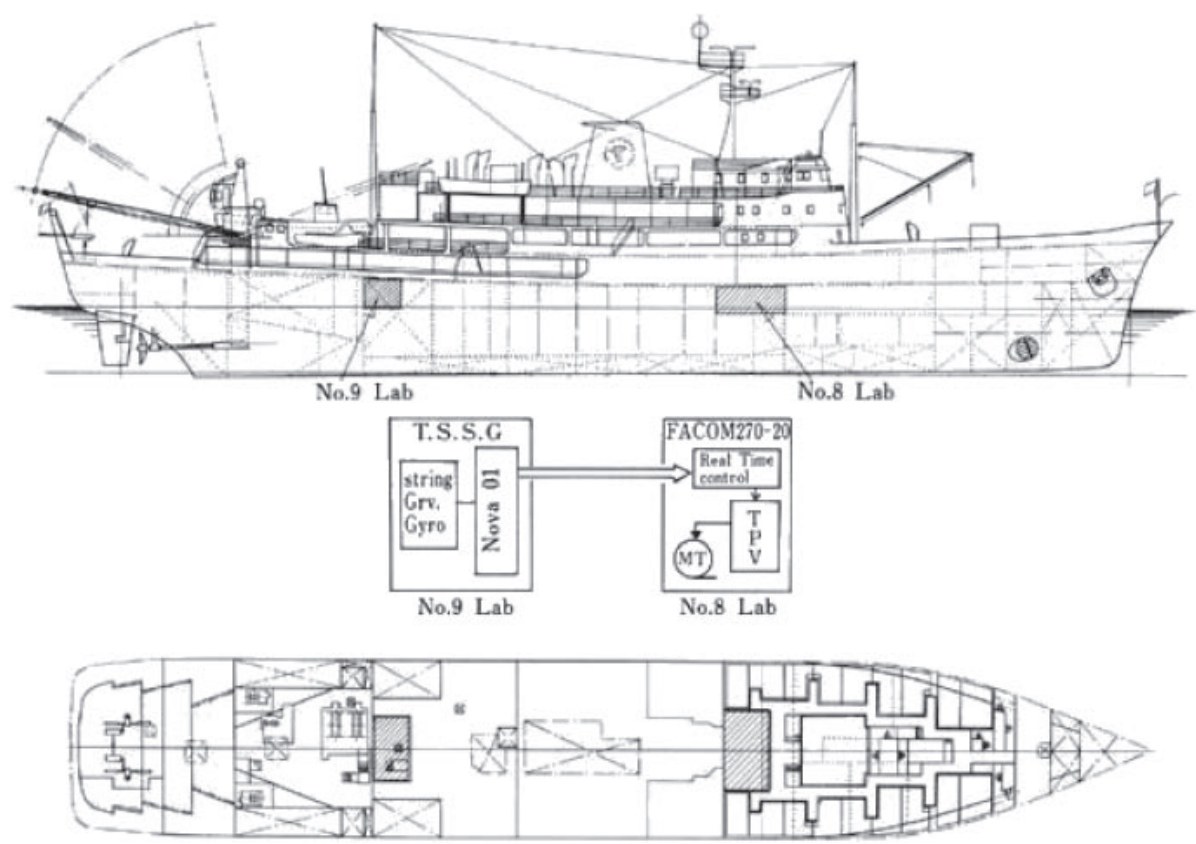

Fig. 9. The research ship "Hakuho-maru". The first model of R/V Hakuho-maru of the ORI (Ocean Research Institute, University of Tokyo) was completed on March 31st, 1967, and then delivered to the ORI. Gross tonnage of the ship is 3200 tons and she was constructed at the Shimonoseki shipyard of Mitsubishi Heavy Industry, Ltd. From the planning stage of the ship, the ORI had made careful considerations about not only a gravity meter but a computer room, where a FACOM 270-20 computer was installed in 1967.

two tops. The on-line data processing system was also improved with a new computer NOVA-01 that was small and convenient for on-line processing. Sampling interval of the vertical acceleration became $0.02 \mathrm{sec}$, and it was no longer necessary to correct the second order effect (Eq. [3]). Observed results were again recorded on paper tapes by using a teletypewriter as 8-bit data. Examples of the tapes are shown in Fig. 10. At that time, Mr. Hiromi Fujimoto (later, Professor at Tohoku University) conducted the system upgrade. Figure 11 shows the paper tapes piled up in front of a wall in our institute.

A serious trouble happened in the new system during a cruise from Tokyo to Brisbane in 1979. Our gravity party at home communicated with the staff in our onboard laboratory through amateur radio, and was told that they found that the transformer in the power supply of the computer was burned out. The main cause was suspected to be a "voltage surge" in the power supply from the motor generator of the ship that occurred by the sudden turning on the switch of a "centrifugal separator" that used the common power supply with our computer. A power transformer was shipped to Brisbane, and the onboard party completely repaired the computer while anchored at the port.

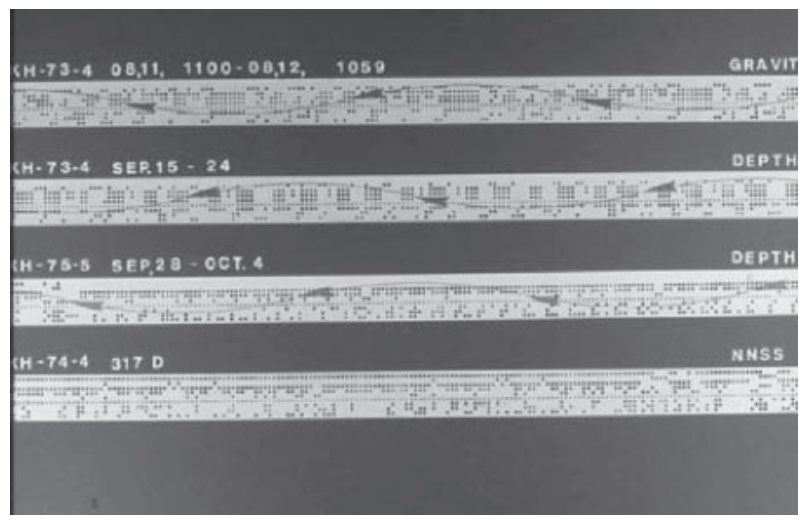

Fig. 10. Contents of the paper tapes. The online data processing for the TSSG-72 started in 1973. The output from the computer was paper tapes. After supper every day during a cruise, volunteers punched the data of the depth of the sea on a paper tape of a teletypewriter, reading the analogue records of the echo sounder. As for the ship position, the NNSS (Navy Navigation Satellite System) receiver supplied the data in paper tape format. Figures were contents of these paper tapes, and a computer for off-line processing calculates the results from these three kinds of paper tapes.

4.5 Problems of ship's position and velocity. The value of the measured gravity changes because the speed around the Earth's rotation axis varies 


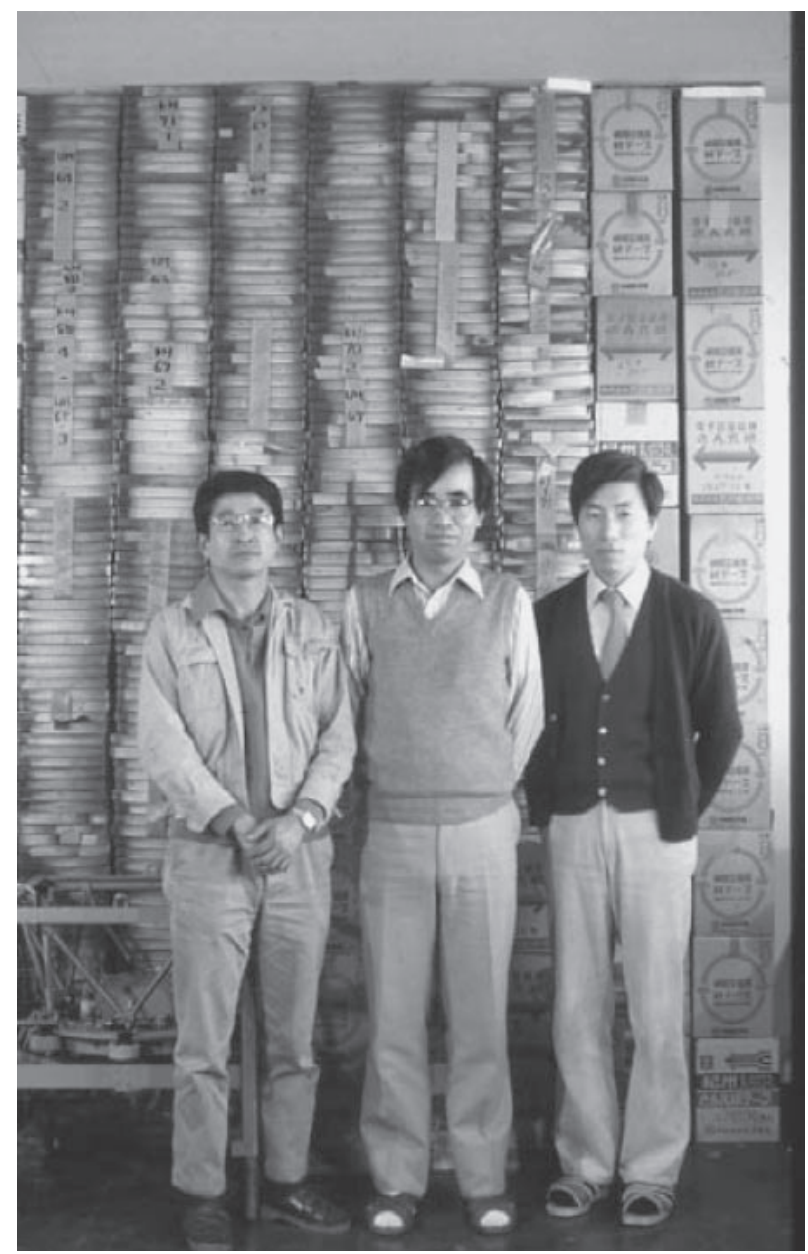

Fig. 11. Good-bye to "paper tapes". The contents of paper tapes piled up in front of the wall of our laboratory were all transferred to magnetic tapes, and all the paper tapes were discarded. This is a memorial picture before discarding them. On the left is technical official Kin-ichiro Koizumi, who took care of the gravity meter. In the center is technical official Akinori Uchiyama, who chiefly took care of the on-line and off-line computers. On the right is research assistant Hiromi Fujimoto who was responsible for the data processing, and he carried out great work in interpreting the gravity data (present, professor of Tohoku University).

according to the east-west velocity component of the ship; gravity is a vector sum of the attraction of the Earth and the centrifugal force of its rotation. This effect is called the "Eötvös effect". L. Eötvös (18481919), a Hungarian geophysicist who designed the instrument to measure the gradient of gravity potential, discovered the effect during his attempt to measure the universal constant of gravitation. Because the centrifugal force becomes large, the measured gravity value becomes small when the ship moves eastward, and a positive correction is neces- sary. For instance, when a train runs eastward at a speed of $300 \mathrm{~km} / \mathrm{h}$ in Japan, observed gravity becomes smaller by about $0.1 \%$. To measure gravity with an accuracy of $1 \mathrm{mgal}$, it is necessary to know the ship's speed in the east-west direction with an accuracy better than 0.1 knots. The requirement was a difficult problem, until the "Global Positioning System (GPS)" came to use.

The following formula shows the Eötvös correction in the unit of mgal:

$$
\Delta g=2 \omega v \sin \theta \cos \varphi * 0.514 * 10^{5} \approx 7.49 v \sin \theta \cos \varphi
$$

where $\omega$ is the angular velocity of the rotation of the Earth $\left(=7.29 \times 10^{-5} \mathrm{rad} \mathrm{s}^{-1}\right), v$ is ship's velocity in knot $\left(1 \mathrm{knot}=0.514 \mathrm{~m} \mathrm{~s}^{-1}\right), \theta$ is ship's direction measured from the north, and $\varphi$ is the latitude of the observation.

The difference of the ship position in a finite time interval gives an average speed of the ship. Celestial position fixing based on observations of inclination of the stars and the sun was usually made twice a day, in the morning and in the evening. Based on the measurements, we can calculate a position at a certain interval through the interpolation of the navigation data of the speed relative to the seawater and the ship's direction given by the gyrocompass. In 1973, the celestial positioning on the "Hakuho-maru" was replaced by a satellite navigation (NNSS). In the western Pacific, the moment-to-moment position was also determined by the Loran $\mathrm{C}$ (North West Pacific Chain of the Loran). I suppose that the research ships now use the GPS.

4.6 Topography and gravity. As is shown in the profiles in Fig. 17, for example, free-air anomalies are well correlated with the seafloor topography. Accurate bottom topography should be known when we try to interpret the structure below the surface of the bottom. There is a convenient device called "Echo Sounder" to measure the seafloor topography from a two-way travel time of an acoustic signal. When our shipboard gravity meter was completed, I thought that the echo sounder was already a perfect machine. However, the sounders we used did not work and we could not get the data of bottom topography in many cruises, while the gravity meter worked well.

Consequently, I studied the structure and mechanism of the echo sounder during a cruise in the Indian Ocean. There were few echo sounders in Japan in 1960's that could measure up to a depth of 6000 meters. In case they measured the depth, they 
did it in a calm sea with a smooth bottom. In the "International Expedition of the Indian Ocean" in 1963 where the training ship "Umitaka-maru" was used, the echo sounder of the ship had a difficulty in measuring the depth in the sea area south of Indonesia where the sea temperature was high. Captain K. Ozawa, Quartermaster A. Nakamura and I worked hard to improve the echo sounder installed at the bottom of the ship. Working in the hot and damp room, sweat was pouring down. When I returned to the deck from the bottom of the ship, one of my friends laughed at me, thinking that I had put a wave from the Indian Ocean onto my head.

An echo sounder was installed on the research ship "Tansei-maru" (the first one was 270 tons constructed in 1963), the first research ship that the Ocean Research Institute had built. However, I knew from some trial results that this echo sounder would have difficulty in measuring the depth deeper than 6000 meters. Therefore, I refused to sign on the blue print of the device. Then a newly designed echo sounder was installed on "Hakuho-maru" constructed in 1967. Together with the shipboard gravity meter, the first cruise KH67-1 was executed. Though the shipboard gravity meter worked without any trouble, the record on the paper of the echo sounder was white (no record of the sea floor topography). However, an official report that "the result was good enough" was submitted.

The emitter and receiver of the echo sounder were installed in a place toward the bow in the central part of the ship. One of probable causes for this unsatisfactory result was the bubbles generated in the bow of the ship. If this is the case, the problem is not with the echo sounder but with the shape of the bow of the ship. When the ship was in dock in 1967, the receivers of the echo sounder were temporarily installed at four places on the bottom of the ship: the bow, the port and the starboard sides, and the rear of the emitter. This was tried in order to understand how the bubbles were negated at the bottom of the ship. It happened that the welding of the receiver at the port side came off, and the receiver banged against the hull. On a calm day near the equator, the hull was intentionally inclined by about $30^{\circ}$, as an old sailing ship did when they washed the ship's bottom. Then the engine staff detached the receiver. We made a towing type receiver by using piezoelectric elements for an acoustic exploration receiver while at anchor in Rabaul, New Britain Island, and we tested it. The results were better than any in the past. Thereafter, the soundings were completed. The emitter and

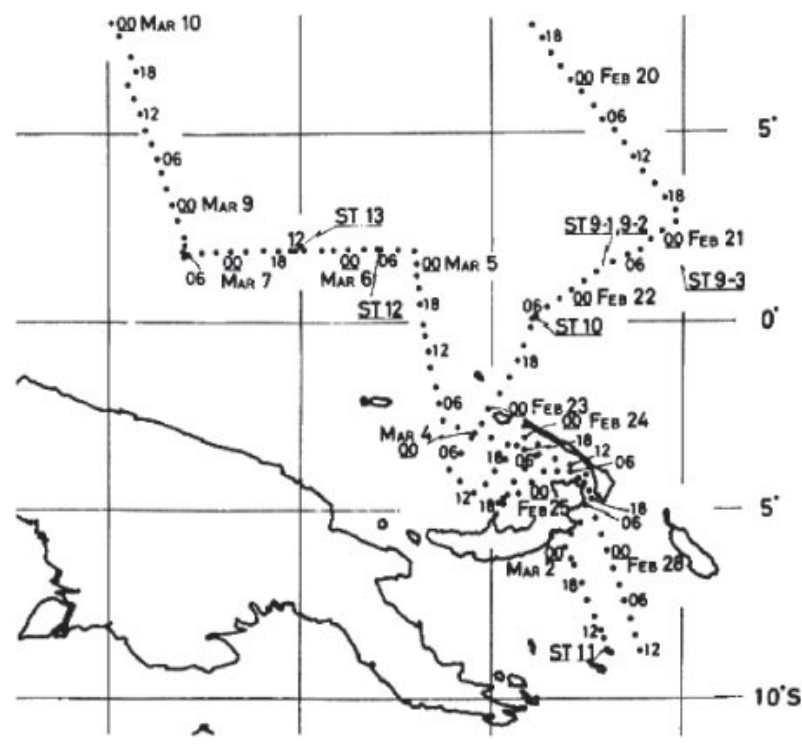

Fig. 12. Rendezvous in the Bismarck Sea (ship track). R/V "Hakuho-maru" set sail from Rabaul, New Britain Island, at 05:00 March 2nd, 1971, to the rendezvous point with a research ship "Vitiaz" from the Soviet Union. Two research ships compared the measured value of each gravity meters, while running side by side (from 06:00 March 5 to 06:00 March 7) at an equal speed on the Caroline basin where the ocean bottom is flat.

receiver were transferred from the central part on the bottom of the ship to the bow in 1968 .

4.7 Comparison of gravity measurements. During a research cruise of the "Hakuho-maru" KH71-1 cruise in 1971 (Fig. 12), a comparison measurement was done with the gravimeter made in Germany (Askania Sea Gravimeter Gss II) on board the research ship "Vitiaz" of the Soviet Union (Fig. 13). The two ships sailed at the same speed, side by side, mutually seeing the bridge in calm Caroline Basin of smooth bottom. The contents of a joint observation, while sailing to "Deep Sea Drilling Site 62 ", were as follows:

(1) Measurements of gravity and terrestrial magnetism, and a comparison of the results.

(2) By using a sound source from an air compressor and towing underwater hydrophones a team on "Hakuho-maru" measures the thickness of the sediment on the bottom.

(3) A team on "Vitiaz" drops explosives as a sound source every four minutes, and determines the sedimentary structure deeper than the depth determined by the second observation.

We carried out the work from 15 o'clock March 6 to 06 o'clock March 7. The result showed a remarkable agreement of 1.8 mgals. Scientists on 


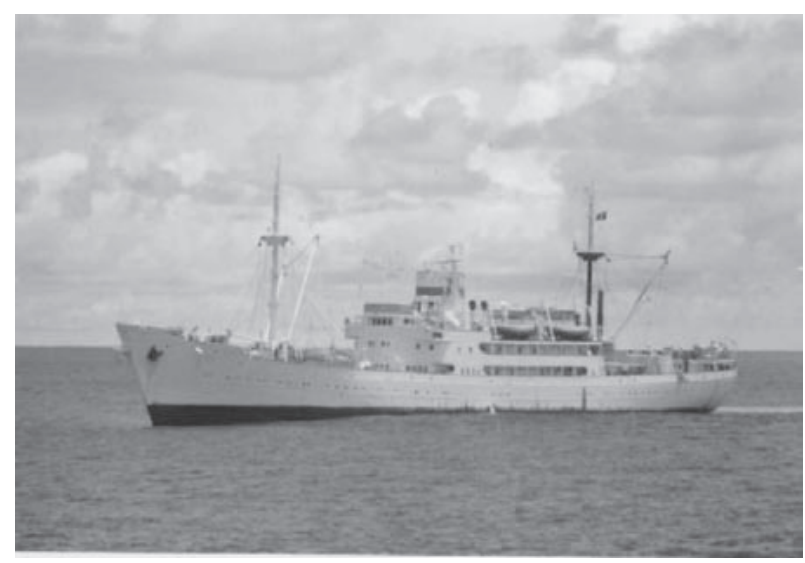

Fig. 13. The USSR research ship "Vitiaz". At 11:00, March 06, the captain recognized a white ship near the horizon, 30 miles north of our ship.

both ships were satisfied with the results, which were close to the expected accuracy of corrections for longterm drifts of the gravity sensors. However, quite unfortunately, a technician on "Vitiaz" died in an accident of the explosion of a detonator.

In 1972, a LaCoste \& Romberg shipboard gravimeter of the Woods Hole Oceanographic Institution was installed in a gravity laboratory of "Hakuho-maru", as one of the Japan-U.S. Science Cooperative Projects. We compared the results of the gravity meters during two cruises in 1972 . We had greatly improved the gravity meter TSSG, chiefly on the vertical gyroscope. The comparison means the test whether the new TSSG was successful or not. Except in cases of sudden change in the course or speed of the ship, the observed gravity values agreed with each other within 1 mgal.

4.8 Estimate of the instrumental errors. Generally speaking, instrumental errors can be evaluated from the wave number spectrum of the observed results. The origin of gravity anomalies exists below the bottom of the deep sea. Therefore, gravity anomalies of short wave lengths should become small with the water depth according to the potential theory. On the other hand, the errors of instrumental origin should have a white spectrum approximately. For instance, when we examine the spectrum of gravity from the Bering Sea expedition, we divided the spectrum of gravity into two groups: a group in which the amplitude becomes small in short wavelength and a group where the data are not correlated with the wavelength (Fig. 14). The data from the latter correspond to the instrumental errors.

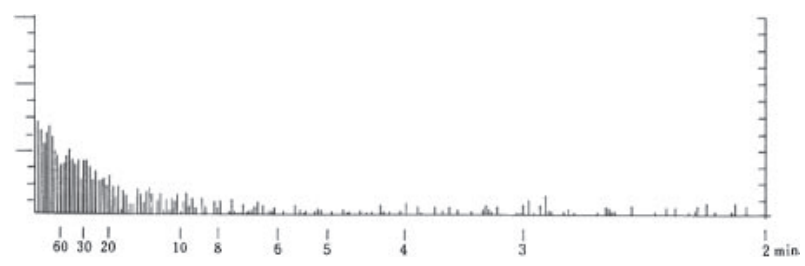

Fig. 14. Estimate of instrumental errors. The figure shows variations in the amplitude of the spectrum of observed gravity values with period in minutes. The spectrum seems to consist of two groups. In the areas of periods longer than about eight minutes, the amplitude becomes small as the period decreases. On the other hand, the amplitude is irrelevant to the period shorter than six minutes. By synthesizing the latter group, we concluded that the mechanical error margin was $0.5 \mathrm{mgal}$ or less.

By analyzing the data of the latter group, we found that a mechanical error margin was $0.5 \mathrm{mgal}$ or less.

There were many observational points where we had passed during several cruises when we plotted the observed gravity data obtained from 1962 to 1980 . We examined the cross-over errors at these points, and found that they were several mgals or less.

\section{Mapping of gravity anomalies at sea}

5.1 Gravity measurement in the Japan Sea. While I have various memories from each gravity cruise, the cruise of the Japan Sea is the most unforgettable one. We carried out gravity measurement in the Okhotsk and Japan Seas in the spring of 1969. We planned to let "Hakuho-maru" enter the Okhotsk Sea immediately after the ice thawed. Entering Okhotsk through the passage between Kunashiri and Etrofu Islands in northern territories of Japan is the shortest course. If it follows the international law of "three nautical miles of territorial waters", this passage is within international waters and we can sail freely. However, if it follows the law of the Soviet Union insisting "twelve nautical miles of territorial waters", the passage is Soviet territory. It was the opinion of the Ministry of Foreign Affairs, which insisted on "three nautical miles of territorial waters", that there was no reason why Japanese people should get permission from the Soviet Union for sailing the passage. Debate continued until departure. In the end, we abandoned the passage, extending the schedule for two days, and entered the Okhotsk from the north side of Urup Island.

Around the same time, a US explore ship "Pueblo" encroached in the territorial waters of North Korea, and the situation in the Japan Sea was tense. Cautious freighters of the Nakhodka sea route painted the "rising-sun flag" on the side of the 
ship, as in the period of the World War II. "Hakuhomaru" had a big flag of a rising sun but to save money they got rid of it later. Fortunately, we did not encounter a situation when we needed to use the flag. However, while we were working at the "Yamato Bank" near the center of the Japan Sea, I saw a warship coming towards our ship flashing a signal. Chief radio operator understood the Morse code as "WHAT/WHERE". The warship continued to circle around our ship until we flew the flags showing the name of the ship (HAKUHO-MARU) and our next port (NAKHODKA). Two Soviet scientists had embarked from Otaru to this observation. I bantered with them saying "A warship from your country came". Through a pair of binoculars, they recognized that the ship belonged to the U.S. navy. I bantered with them again seeing the face of anxiety "Do not worry, there's no problem".

We, for the first time, visited the port of Nakhodka during this cruise. Immediately after departing from the Niigata port in May 29, 1969, we received an official telegram from the Soviet to the Ministry of Foreign Affairs that the gravity measurement in Nakhodka and inside the harbor was not permitted. This was a reply to our inquiry for the permission of the gravity meter calibration in the Nakhodka quay. It was an unexpected serious problem for us because interruption of the measurement could cause a step in the observed gravity values. At the end of discussion among us, we informally continued the gravity measurement during the port call. In response to the uncooperative reply, the Japanese consulate there later sent an official report that the Soviet government did not offer any convenience for the Nakhodka port call of "Hakuho-maru". It then brought about a high barrier for Soviet researchers to carry out gravity connection between Moscow and Tokyo. It took three years to remove the barrier.

The Japan Sea is small, and even the northern part is within a distance of a day trip from Japan. Later we measured gravity in the northern part on board the training ship "Umitaka-maru". The captain Ozawa taught us how to catch northern pink prawns in Hokkaido coast during the daytime, and let us measure gravity while approaching the coast of Primorusuka district at night.

5.2 Mapping of gravity anomalies in and around Japan. We compiled the maps of free-air and Bouguer gravity anomalies in and near Japanese waters, based on the data from 1962 to 1971 obtained with the TSSG. ${ }^{9), 10)}$ Mainly three ships worked for this mapping: "Takuyo" (700 tons), "Umitaka-maru" (1,500 tons), and "Hakuho-maru" (3,200 tons).

I took serious efforts to make the map, based on the data recorded on about fifty sheets of navigation charts. A wide room was necessary to display the whole chart to draw a contoured gravity map. A newly built, unused room of the Ocean Research Institute was used for this work. The gravity contour lines were drawn on the charts that were displayed over the floor and they were reduced to the size of a single sheet of newspaper. I had some difficulties in publishing these results, but finally the University of Tokyo Press kindly undertook the publication. To avoid misunderstanding, we stated in the publication contract that any profit from the publication will belong to the Ocean Research Institute and not to me. The cover of the finished book was silver colored with round holes, and parts of the contour lines of gravity anomalies can be seen though the holes. It was as fancy as a fashion magazine.

When I was awarded the Japan Academy prize in 1974, the Emperor Showa looked at both the map and the second model of the TSSG. It was only half a year after the map was completed, and it seemed as if it was printed for this event. I forgot to write the year of the publication on the map, probably because I was in such a hurry to publish it.

On June 21, 1977, when The Prince (present Emperor) visited our ship "Hakuho-maru", I was delighted to show him a narrow gravity meter room, a gravity meter and this map. What I wanted to mention to The Prince about this map was that it was the first data set of gravity anomalies in the Japan Sea. The gravity in the Japan Sea was planned to have been measured in 1936 after Professor Matuyama measured the gravity of the neighboring sea of the Ogasawara Islands by using a submarine. However, he could not accomplish this plan due to the increased tension in the international affairs and we completed the measurements with the shipboard gravity meter years later. Moreover, I think that it was one of the great results to find a large negative gravity anomaly on the landward side at the junction area of the Nankai Trough and the Ryukyu Trench.

5.3 Mapping of gravity anomalies in the northwest Pacific. The measurement of gravity at sea was continued in almost all the cruises of the $\mathrm{R} / \mathrm{V}$ "Hakuho-maru" for nine years after completing the map of gravity anomalies around Japan in 1973. When I was unable to accompany the cruises, Mr. Kin-ichiro Koizumi, technical official in our labora- 


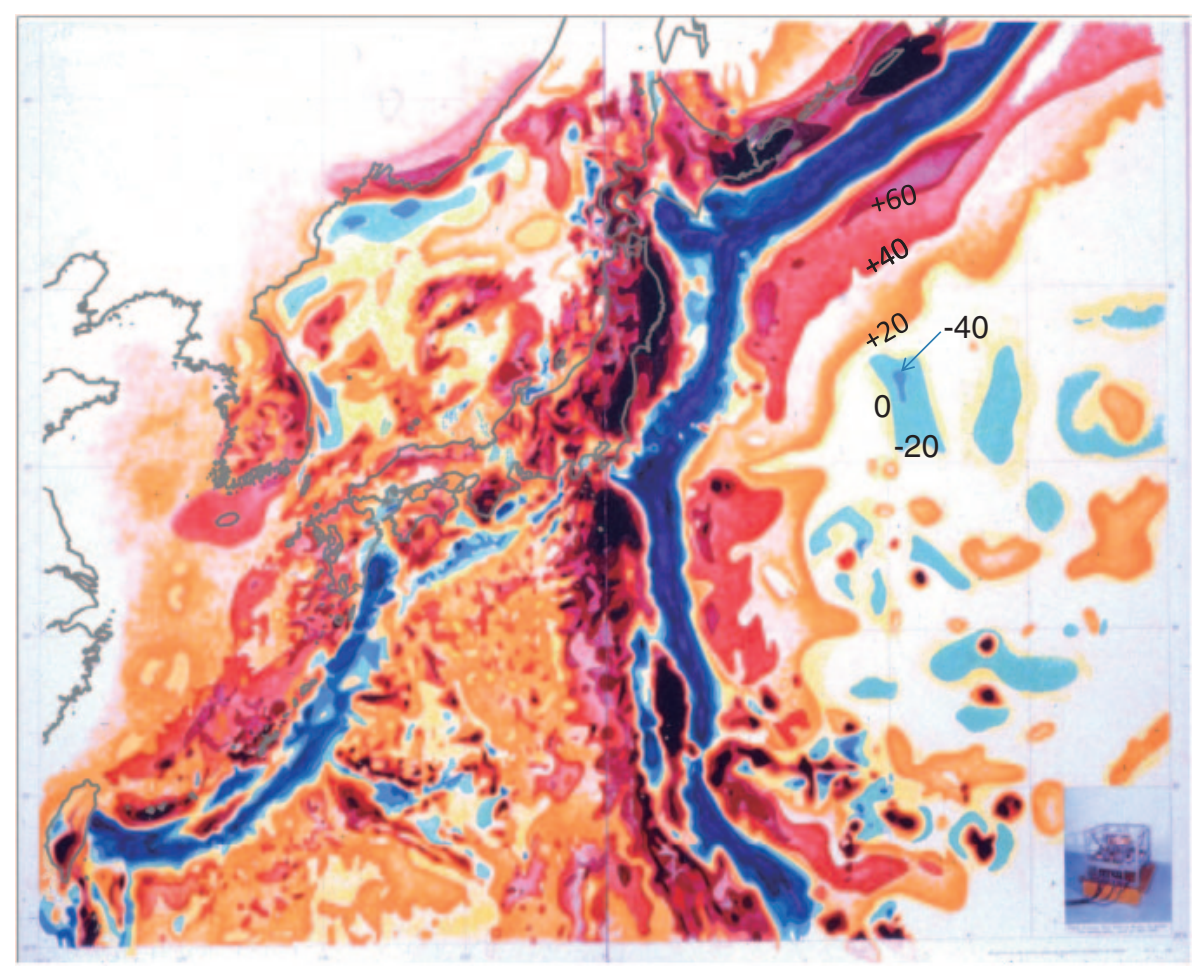

Fig. 15. A map of gravity anomalies in the northwest Pacific Ocean compiled in 1982 by using the data from 1962 to 1980 . Contour interval is 20 mgals as is shown on some contour lines. Reddish colors show positive anomalies, and bluish colors negative anomalies. I exhibited this map in the hall of the Federation of Economic Organizations in Tokyo, where the first General Assembly of the IAG (International Association of Geodesy) was held in 1982. Beside the map, I displayed the twenty-sized oil painting of the "Hakuhomaru". The map was also exhibited in the hall of the Science Council of Japan in 1983 celebrating the one hundredth anniversary of the International Geophysical Year.

tory, operated the gravity meter in my place. However, because the adjustment of the vertical gyroscope of the gravity meter was complex, I had to adjust it before each cruise. As a result, I saw off every time when the ship set sail and welcomed her home when she returned from the cruise, and I received the nickname "a father at the quay". There was, at that time, a popular song called "a mother at the quay" for a woman awaiting her son to come back home from the war every day.

The observed results up to 1980 were compiled on to the maps of gravity anomalies. ${ }^{11)}$ The Ocean Research Institute pleasantly took care of the budget for the map publication this time. I inserted sketches of views drawn from the ship in the reference book of the maps. ${ }^{11}$ I did this secretly at the proofreading stage, in the printing office. I painted one of the copies of the maps in color (Fig. 15); it was displayed in the hall in the Federation of Economic Organizations in Tokyo where the first General Assembly of the International Association of Geodesy (IAG) was held in 1982 . The map is a summary of 30 years of my work. I displayed the map together with a twentysize oil painting of "Hakuho-maru", in the stone piled dock of the Yokohama shipyard of the Mitsubishi Heavy Industry, Ltd. The picture is quite special for me. I always place the picture near myself as Leonard da Vince always brought the picture of the "Monna Lisa" with him.

The poster of the IAG meeting illustrated a "whale's-eye" view of undulation of geoid in and around Japan" that was calculated from the gravity data (Fig. 16). To save money for this congress I worked hard as "Tomoda the artist" to design the poster. I brought the original copy to the Dainihon Printing Co. Ltd. and had it printed exactly as I wanted.

5.4 Features of free-air gravity anomalies in the northwest Pacific Ocean. At first glance, it seems that the complexity of the gravity anomalies is quite different between the east and west sides of the Izu-Ogasawara to Mariana Trenches. ${ }^{12)}$ I interpreted that this difference results from both the difference in the mean depths and the complicated bottom 


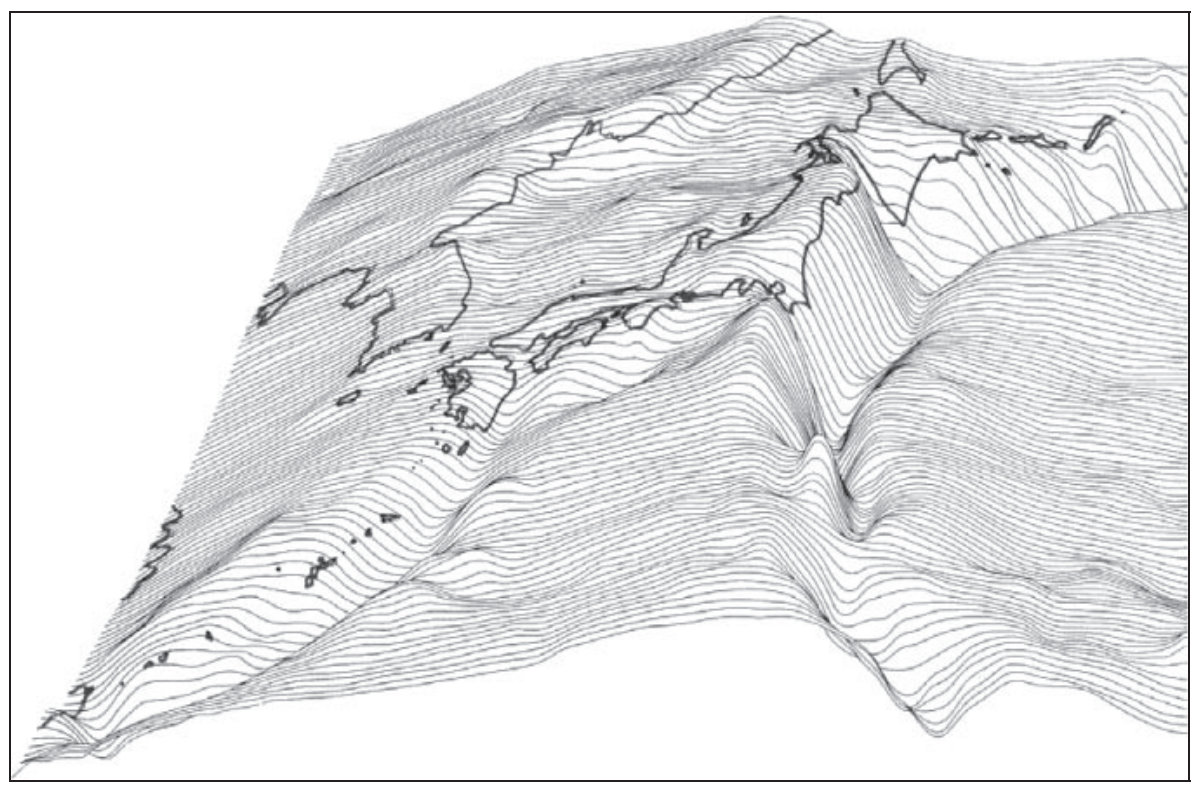

Fig. 16. Undulation of geoid in and around Japan. When the data of free-air gravity anomalies are integrated, the shape of the Earth (undulation of the geoid: height of average sea surface from the reference ellipsoid) is given. The geoid was locally lower by about $20 \mathrm{~m}$ on the sea above the Japan Trench.

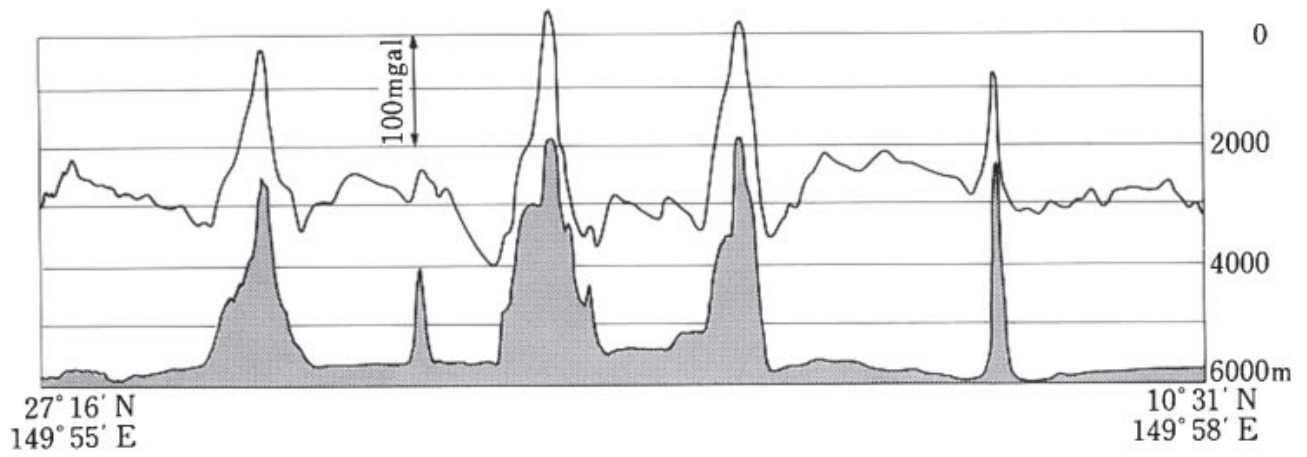

Fig. 17. Cross sections of seamounts. Profiles of the free-air gravity anomalies (top) and the bottom topography (bottom) along about the 150-degree E meridian crossing the crests of seamounts.

topography in the Philippine Sea (Shikoku Basin) as well as from more abundant observation data in the area. The mean depth is about 3,000 meters in the Philippine Sea and is about 6,000 meters in the Pacific basin in the east. Therefore, the gravity anomalies due to the topography in the west side should not be as attenuated as that in the east side.

Characteristics in the free-air gravity anomalies are summarized as follows ${ }^{12), 13)}$ :

1) A large negative anomaly runs along a trench, and this anomaly runs side by side with a large positive anomaly in the island arc.

2) The axis of the negative gravity anomaly lies on the landward side of the axis of the topographic trench. The two features mentioned above have been known since the pendulum measurements on board submarines.

3) A large and sharp positive gravity anomaly is observed above a seamount as is shown in Fig. 17. We also found that a wide "negative gravity moat" is surrounding the positive anomaly. Distribution of these anomalies associated with the isolated seamount is like the figure of the "zeroth order Bessel function".

4) Though not so large as the positive gravity anomaly in the island arc, there is a positive gravity anomaly seaward of the trench. Its amplitude is usually about 50 mgals, and the 

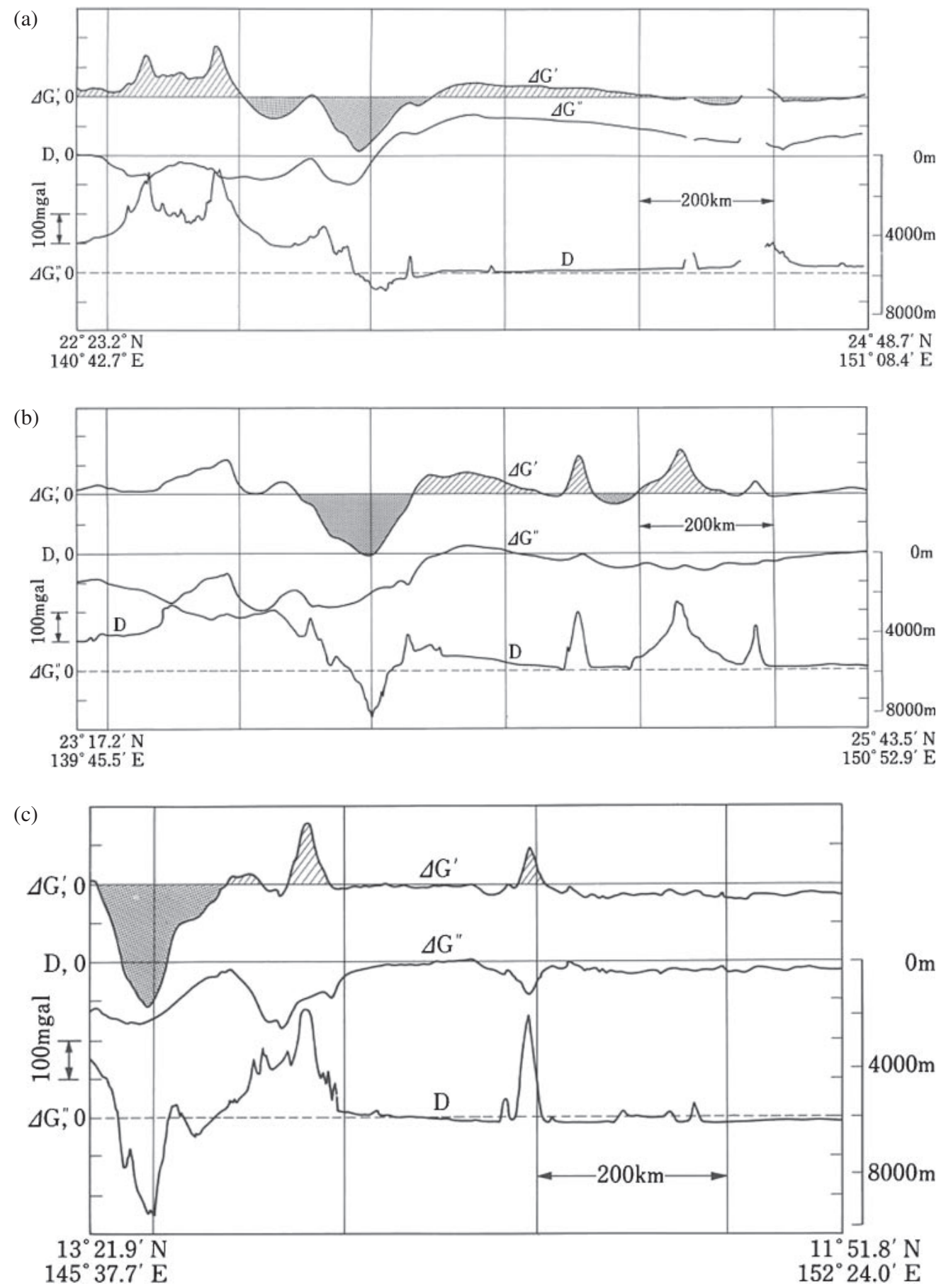

Fig. 18. Cross sections of trenches. "Positive free-air anomalies seaward of the trench" indicating the interaction between seamounts and the trench: $\Delta \mathrm{G}^{\prime}$ : free-air anomalies, $\Delta \mathrm{G}^{\prime \prime}$ : Bouguer anomalies, and D: bottom topography. (a), Gravity profile when a seamount is located far from the trench. (b), Gravity profile when a seamount is located near the trench. (c), An example of cancellation of the outer gravity high seaward of the trench by the low gravity around the seamount.

horizontal extent is as much as $300 \mathrm{~km}$ from the profile in Fig. 18a. "The positive anomaly seaward of the trench" is an important phenom- enon related to the origin of "subduction" of the oceanic plate. The following features are related to this phenomenon. 
5) The positive gravity anomaly seaward of the Ryukyu Trench and that of the Nankai Trough were found to be some $1 / 3$ in the amplitude compared with that of the Japan Trench or that of the Izu-Ogasawara Trench.

6) The positive anomaly seaward of the trench is not observed when a seamount or a seamount group is near the trench. I think it shows the interaction between the seamounts and the trench (Figs. 18b, 18c).

7) A large negative gravity anomaly comparable to the negative anomaly caused by a trench exists in the landward region where the Kurile Trench intersects with the Japan Trench as well as in the region where the Nankai Trough intersects with the Ryukyu Trench. I think that this anomaly shows the trench-trench interaction.

8) There is a positive gravity anomaly of +300 mgal or more in the Ogasawara Islands in the west of the Ogasawara Trench. In addition, a negative anomaly of $-150 \mathrm{mgal}$ is found west of these islands. As for this negative anomaly, I think that it shows the leap of the trench axis caused by the collision of the Ogasawara Islands and the old Ogasawara Trench.

\section{Postscript and acknowledgements}

In the summer of 2005, I was asked to contribute a manuscript on my life-long scientific research, and I started to prepare the manuscript. However, illness caused a delay in finishing up the manuscript, and the final version was submitted in March 2007. During this course, I owe very much to Prof. Hiromi Fujimoto, Tohoku University and Mr. Toshihiko Karato, University of Virginia for correcting the scientific contents and English expressions. I would also like to express my thanks to Dr. Tamio Yamakawa, who initially asked me to write the paper and continually encouraged me.

\section{Editorial}

The original manuscript of this article was submitted to the PJA-B from the late Prof. Tomoda, M.J.A. in March 2007. Unfortunately during the editorial process the author got sick and passed away in December 2007. He left a manuscript written in a style of a personal memoir and a considerable editorial work (modification/addition) was supposed to be needed and hence it was postponed. In this year (2010) Prof. Hiromi Fujimoto at Tohoku University and Prof. Shun-ichiro Karato at Yale University, both having been colleagues of the late Prof. Tomoda at Ocean Research Institute, University of Tokyo, kindly offered to take over this work. They mostly made additions in Sections 1 and 2 in order to help a reader understand Prof. Tomoda's work better, leaving substantial part of the author's memoir in the original form. The editor in charge is grateful for their voluntary dedication to the work which has made the publication possible.

\section{References}

1) Vening Meinesz, F.A. (1929) Theory and practice of pendulum observations at sea. Publ. Netherlands Geod. Comm., Waltman Jr. Delft.

2) Heiskanen, W.A. and Vening Meinesz, F.A. (1958) The Earth and Its Gravity Field. McGraw-Hill, New York.

3) Worzel, J.L. (1965) Pendulum Gravity Measurements at Sea, 1936-1959. Interscience Publishers, John and Willey \& Sons.

4) Matuyama, M. (1934) Measurements of gravity over the Nippon Trench on board the I.J. Submarine Ro-57. Proc. Imp. Acad. 10, 626-628.

5) Tsuboi, C. (1934) Improved apparatus for taking gravity measurements at sea on board. Proc. Imp. Acad. 10, 640-642.

6) Tomoda, Y. and Kanamori, H. (1962) Tokyo Surface Ship Gravity Meter $\alpha-1$. J. Geod. Soc. Japan 7, 116-145.

7) Gilbert, R.L.G. (1949) A dynamic gravity meter of novel design. Proc. Phys. Soc. B 62, 445-454.

8) Tsuboi, C., Tomoda, Y. and Kanamori, H. (1961) Continuous measurements of gravity on board a moving surface ship. Proc. Jpn. Acad. 37, 571576.

9) Tomoda, Y. (1973) Maps of Free-air and Bouguer Gravity Anomalies in and Around Japan. University of Tokyo Press, Tokyo.

10) Tomoda, Y., Segawa, J. and Tokuhiro, A. (1970) Free-air gravity anomalies at sea around Japan measured by the Tokyo Surface Ship Gravity meter, 1961-1969. Proc. Jpn. Acad. 46, 10061010.

11) Tomoda, Y. and Fujimoto, H. (1982) Maps of gravity anomalies and bottom topography in the western Pacific and reference book for gravity and bathymetric data. Bull. Ocean Res. Inst. Univ. Tokyo 14, 1-158.

12) Tomoda, Y. and Fujimoto, H. (1981) Gravity anomalies in the northwestern Pacific and their geophysical interpretation. Proc. Jpn. Acad., Ser. B 57, 359-361.

13) Tomoda, Y. (1983) Marine geodesy of the northwestern Pacific. Mar. Geod. 7, 11-38.

(Received Mar. 4, 2007; accepted Aug. 30, 2010) 


\section{Profile}

Yoshibumi Tomoda was born in 1926 and started his research career in 1950 with studies on marine gravity at the Faculty of Science of the University of Tokyo. He succeeded in developing a gravimeter for measurements on a surface ship in 1961, which Prof. Chuji Tsuboi had endeavored without success. Since precise measurement of gravity on a swaying vessel required many technological breakthroughs, his work was a leading edge of scientific use of new technologies, such as a computer and a quartz clock. He also played key roles not only in the instrumentation for marine geology and geophysics but in developing advanced research ships and submarine research vehicles. He was promoted to a Professor at the University of Tokyo in 1969. He not only performed gravity studies in the western Pacific but led marine geophysical researches in

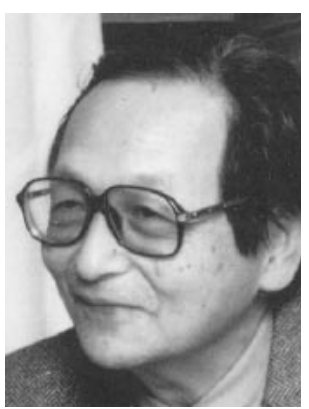
Japan. He was awarded the Japan Academy Prize in 1974 for his pioneering studies in marine gravimetry, and was elected a member of the Japan Academy in 1992. 